Bubble Behavior and Heat Transfer of Nucleate Pool Boiling on Micro-Pin-Finned Surface in Microgravity

This article has been downloaded from IOPscience. Please scroll down to see the full text article.

2011 Chinese Phys. Lett. 28016401

(http://iopscience.iop.org/0256-307X/28/1/016401)

View the table of contents for this issue, or go to the journal homepage for more

Download details:

IP Address: 159.226.231.78

The article was downloaded on 23/03/2012 at 03:35

Please note that terms and conditions apply. 


\title{
Bubble Behavior and Heat Transfer of Nucleate Pool Boiling on Micro-Pin-Finned Surface in Microgravity *
}

\author{
WEI Jin-Jia(魏进家 $)^{1 * *}$, XUE Yan-Fang(薛艳芳 $)^{1}$, ZHAO Jian-Fu(赵建福 $)^{2}$, LI Jing(李晶 $)^{2}$ \\ ${ }^{1}$ State Key Laboratory of Multiphase Flow in Power Engineering, Xi'an Jiaotong University, Xi'an 710049 \\ ${ }^{2}$ Key Laboratory of Microgravity (National Microgravity Laboratory)/CAS, Institute of Mechanics, Chinese Academy \\ of Sciences, Beijing 100190
}

(Received 8 July 2010)

\begin{abstract}
Nucleate pool boiling on micro-pin-finned surface structure is proposed for efficiently cooling electronic components with high heat flux in microgravity, and was verified by experiments performed utilizing the drop tower Beijing. Micro-pin-fins with the dimensions of $50 \times 60 \mu \mathrm{m}^{2}$ (thickness $\times$ height) and the space of $50 \mu \mathrm{m}$ were fabricated on the chip surface by the dry etching technique. FC-72 was used as the working fluid. Nucleate pool boiling of $\mathrm{FC}-72$ on a smooth surface was also tested for comparison. Unlike much obvious deterioration of heat transfer of nucleate pool boiling on the smooth surface in microgravity, constant heater surface temperature of nucleate pool boiling for the micro-pin-finned surface was observed, even though a large coalesced bubble completely covered the surface under microgravity condition. The performance of high efficient heat transfer on micro-pin-finned surface is independent of the gravity, which stems from the sufficient supply of fresh liquid to the heater surface due to the capillary forces.
\end{abstract}

\section{PACS: 64. 70.Fh, 44. 35. +c DOI: $10.1088 / 0256-307 \mathrm{X} / 28 / 1 / 016401$}

Electronics cooling by using boiling heat transfer in space and in planetary neighbors has become an increasing significant subject due to its high efficiency in heat transfer. However, for the boiling heat transfer in microgravity, the buoyancy effect becomes weak, resulting in a longer stay time for the bubble departure. These may prevent the effective access of fresh bulk liquid to the heater surface in time, resulting in a lower boiling heat transfer performance at high heat flux. ${ }^{[1]}$ How to improve boiling heat transfer effectively in microgravity is an important issue.

A number of active studies have dealt with the enhancement of boiling heat transfer from electronic components by use of surface microstructures that were fabricated directly on a silicon chip or on a simulated chip. These include a dendritic heat sink, ${ }^{[2]}$ laser-drilled holes, ${ }^{[3]}$ micro-re-entrant cavities $(1-3 \mu \mathrm{m}$ in mouth diameter), ${ }^{[4]}$ porous surfaces formed by spraying and painting of alumina particle ${ }^{[5]}$ or copper particle $(3-10 \mu \mathrm{m}$ in diameter $) .{ }^{[6,7]}$ All the above treated surfaces experienced the drawback of severely deterioration of boiling heat transfer in the high heat flux region, and the wall temperature at the critical heat flux $(\mathrm{CHF})$ is larger than the upper limit for the reliable operation of LSI chips, $85^{\circ} \mathrm{C}$. The deterioration of these surfaces performance is caused by a large number of mushroom bubbles staying above the surface microstructure, which prevented the bulk of liquid from contacting the superheated wall for vaporization. Therefore, the enhancement tapers off noticeably as the heat flux approaches the CHF. Under microgravity conditions, the large mushroom bubble is difficult to detach from the surface due to weakness of buoy- ancy force, further worsening the boiling heat transfer. Therefore, these kinds of surface microstructures are not suitable for efficiently cooling high-heat-flux electronics under microgravity condition.

Wei et al. ${ }^{[8-11]}$ have made a series of experimental studies on boiling enhancement by using micro-pinfins $(10-50 \mu \mathrm{m}$ in thickness and $60-200 \mu \mathrm{m}$ in height) which were fabricated by dry etching. From the boiling incipience to the critical heat flux, the micro-pinfinned surfaces showed a sharp increase in the heat flux with increasing wall superheat. The increase of $\mathrm{CHF}$ could reach more than three times that of a smooth chip, and the wall temperature at the $\mathrm{CHF}$ point was lower than $85^{\circ} \mathrm{C}$. In the high heat flux region, although the micro-pin-finned surfaces are covered with large bubbles as smooth or previous microstructured surfaces, the capillary force generated by the bubbles drives plenty of fresh liquid into contact with the superheated wall for vaporization through the regular interconnected structures, as well as improves the micro-convection heat transfer by the motion of liquid around the micro-pin-fins. These produce high heat transfer efficiency until the capillary force reaches its maximum value. The capillary force increases with decreasing fin pitch with a penalty that causes the hydraulic resistances of the wet liquid supply to increase. Therefore, there exists an optimum fin pitch for a compromise. According to our previous studies, ${ }^{[8-11]}$ the fin size of $30-50 \mu \mathrm{m}$ appears to be a preferable size for the design of micro-pin-finned surfaces in the enhancement of nucleate boiling heat transfer.

Following the enhanced boiling heat transfer mechanisms for the micro-pin-finned surfaces, it is supposed

*Supported by the National Natural Science Foundation of China under Grant Nos 50806057 and 10972225 , and the Key Laboratory of Microgravity/CAS for experiments utilizing the drop tower Beijing.

**Email: jjwei@mail.xjtu.edu.cn

(C) 2011 Chinese Physical Society and IOP Publishing Ltd 
that although the bubbles staying on the top of the micro-pin-fins can not be detached soon in microgravity, the fresh bulk liquid may still access to the heater surface through interconnect tunnels formed by the micro-pin-fins due to the capillary forces, which is independent of the gravity level. Therefore, it is our great interest to study the boiling heat transfer performance of micro-pin-finned surfaces in microgravity.

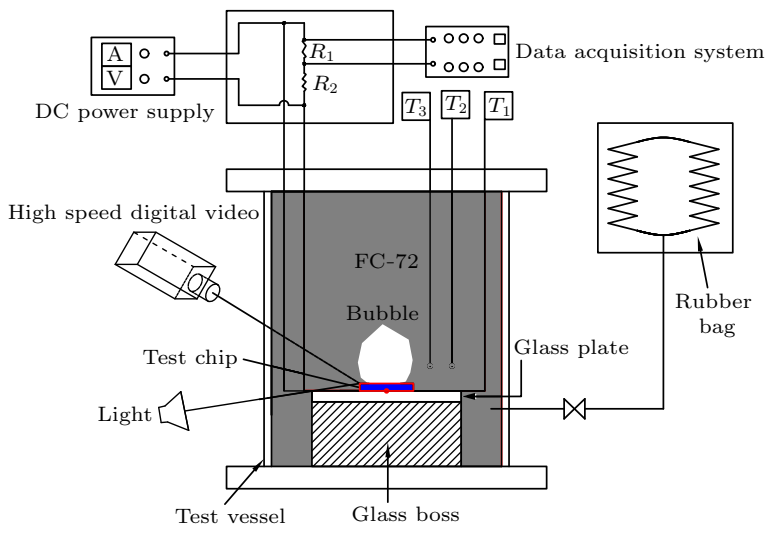

Fig. 1. Schematic diagram of the experimental apparatus.

A simple pool boiling test facility system designed for the present drop-tower experiments is shown schematically in Fig. 1. The boiling vessel was made of polycarbonate, which allowed for visualizing boiling phenomena, with a size of $140 \mathrm{~mm}$ inner diameter and length of $155 \mathrm{~mm}$, and was filled with about 3L of FC-72 as the working liquid. A test section consisting of a silicon chip bonded on a plexiglass plate and fixed on a base made of polycarbonate was horizontally bonded on the base of the test vessel, with the silicon chip facing upward. A nearly atmospheric pressure is maintained by attaching a rubber bag to the test vessel. Also, to determine whether the temperature of the bulk liquid is steady or not before the beginning of microgravity experiment, a K-type thermocouple was used for measuring the local temperature of the test liquid at the chip level, and directly connected to a temperature display monitor for visual observation through a CCD camera. In addition, the local wall temperature at the center of the chip and the local temperature of the test liquid at about $40 \mathrm{~mm}$ from the edge of the chip were measured by two 0.13 -mm diameter T-type thermocouples, which were connected with a data acquisition system (DI710UHS).

The test chip was a P-doped n-type silicon chip with the dimensions of $10 \times 10 \times 0.5 \mathrm{~mm}^{3}$, as shown in Fig. 2. Micro-pin-fins were fabricated on the chip surface for enhancing boiling heat transfer. The fin thickness is $50 \mu \mathrm{m}$ and fin height is $60 \mu \mathrm{m}$. A smooth chip was also tested for comparison. Detailed description about the properties of the test chips were reported in our previous paper. ${ }^{[8]}$ The chip was bonded on a Plexiglass plate using epoxy adhesive and then fixed on the Plexiglass base, which was bonded on the bottom of the test vessel. This facilitated an easy exchange of the test chip and minimization of conduction heat loss. The chip was Joule heated by a direct current. Two $0.25-\mathrm{mm}$ diameter copper wires were soldered by a low temperature solder to the chip side surfaces at the opposite end for power supply. A programmable dc power supply was connected in parallel to two series resistances $\left(R_{1}=5 \mathrm{k} \Omega, R_{2}=100 \mathrm{k} \Omega\right)$ and the test chip. The two series resistances were used to measure the voltages across the test chip in the circuit.

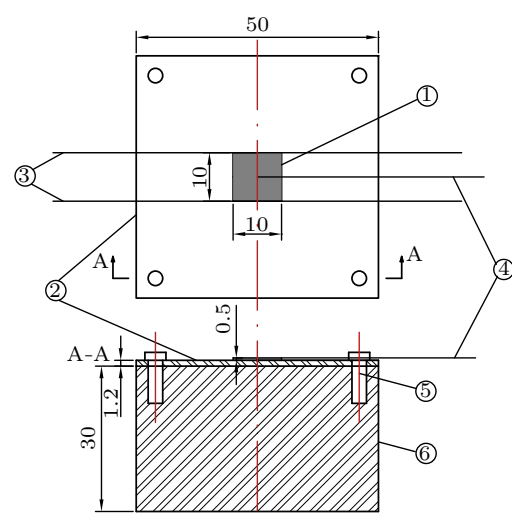

Fig. 2. Details of test section: (1) silicon chip, (2) plexiglass plate, (3) copper lead wire, (4) thermocouple, (5) bolts, (6) plexiglass base.

For the visual observation of liquid-vapor behaviors, a CCD video camera was installed in front of the test vessel at a direction angle of $45^{\circ}$ with respect to the heater surface, and the phenomena were recorded at a speed of 25 frames per second. Simultaneously, a high speed video camera (VITcam CTC) imaging 250 frames per second, at a resolution of $1024 \times 640$ pixels with a shutter speed of $1 / 2000 \mathrm{~s}$, was used along with a Computar lens (MLM-3XMP) to obtain images of the boiling process. The high speed camera was installed in front of the test vessel at a direction angle of $30^{\circ}$ with respect to the heater surface.

Experiments were conducted in terrestrial gravity before the release of the drop capsule and in shortterm microgravity during the free falling in the drop tower Beijing. The facility satisfied the safety criteria to expose the apparatus in the drop capsule to different gravitational environments varying between microgravity $(\mu \mathrm{g})\left(10^{-2}-10^{-3} g_{0}, g_{0}=9.81 \mathrm{~m} / \mathrm{s}^{2}\right)$ in the free falling period and high-g level in the deceleration recovery system $\left(16 g_{0}\right)$.

The test chip was heated by setting a constant input current for the desired heat flux $q_{\text {desired }}$ to initiate boiling on the heater surface. After the heat transfer reached a steady state in about two minutes, the free falling of drop capsule started, which could provide approximately $3.6 \mathrm{~s}$ effective microgravity environment. The high-speed video camera could work for a duration time of $4 \mathrm{~s}$ to get the boiling heat transfer phenomena after an external trigger signal was received. Moreover, the data measurement and the 
video recording were operated simultaneously.
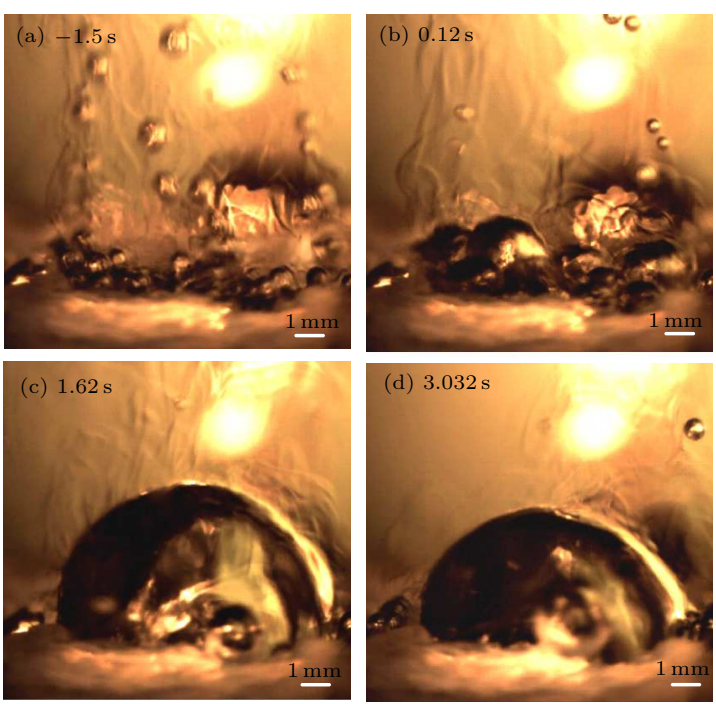

Fig. 3. Bubble behaviors on chip S: (a) $-1.5 \mathrm{~s}$, (b) $0.12 \mathrm{~s}$, (c) $1.62 \mathrm{~s}$, (d) $3.032 \mathrm{~s}$

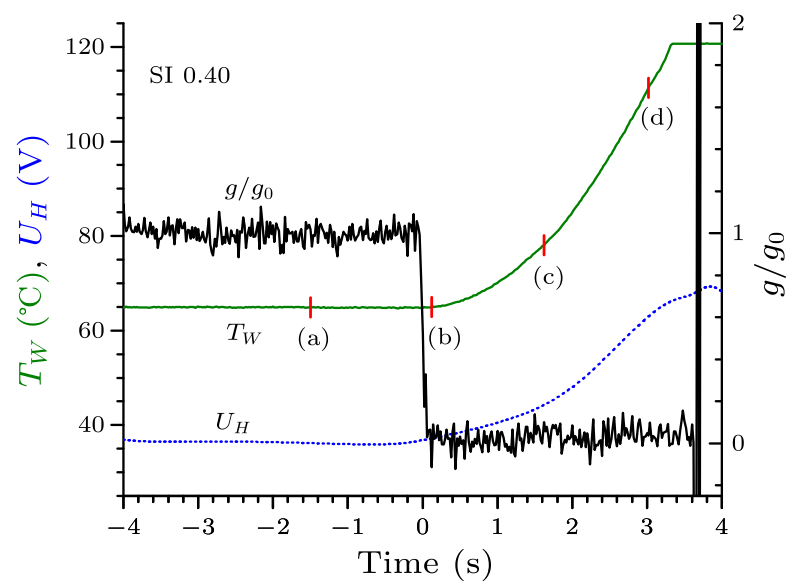

Fig. 4. Variations of surface temperature, heating voltage, and gravity for chip S.

The transition of vapor bubble behaviors and the mean surface temperature of the smooth chip (denoted as Chip $\mathrm{S}$ ) responding to the variation of gravity level for the heating dc current of $0.40 \mathrm{~A}$ (corresponding to a heat flux of $23.6 \mathrm{~W} / \mathrm{cm}^{2}$ ) are shown in Figs. 3 and 4, respectively. The positions of Figs. 3(a)-3(d) are marked on the curves of the mean temperature of Chip S shown in Fig. 4. The liquid subcooling keeps at about $41 \mathrm{~K}$. The time for entering the microgravity condition is set to $0 \mathrm{~s}$. It can be seen that before entering the microgravity condition, the bubbles generate and departure continuously from the heating surface at a steady state due to the effects of buoyancy forces (as shown in Fig. 3(a)). However, at about $0.12 \mathrm{~s}$ after entering the microgravity condition, the vapor bubbles begin to coalesce with each other to form several large bubbles, which attach on the chip surface without departure due to the weakness of buoyancy force (as shown in Fig. 3(b)). With increasing time up to
$1.62 \mathrm{~s}$, the bubbles tend to maintain a hemispherical shape with a large contact area on the heater surface, and almost completely cover the heater surface (as shown in Fig. 3(c)), causing the mean heater surface temperature to rise continuously, as shown in Fig. 4. In addition, it is noted that this large bubble tends to maintain its size due to the balance of the dual processes of condensation at the bubble cap and coalescence with the small bubbles at the base. With further increasing time up to $3.03 \mathrm{~s}$, the vapor bubble gradually becomes oblate in shape and smooth in contour. This is probably attributed to the higher levels of subcooling, resulting in the strong condensation at the bubble cap. This boiling mechanisms are quite analogous to the one described by Zhao et al. ${ }^{[12]}$ The mean heater surface temperature increases significantly. A final flat part of wall temperature does not represent a steady state, which is caused by the upper limit cutoff of the thermocouple instrument. Therefore, the boiling process can not reach a steady state during the short microgravity time duration of $3.6 \mathrm{~s}$ provided by the drop tower. However, the trend of the mean wall temperature can provide some important information for the occurrence of CHF and dry out.
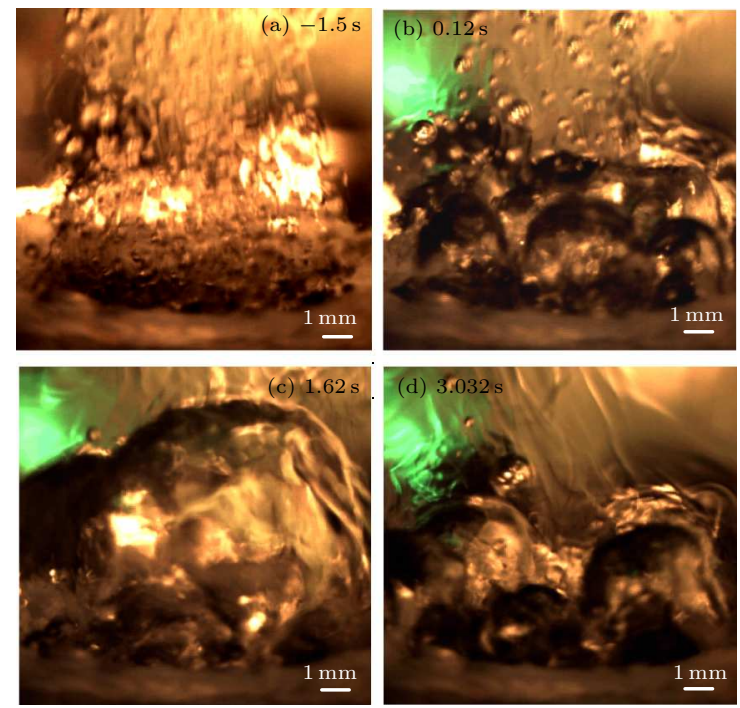

Fig. 5. Bubble behaviors on chip PF50-60: (a) -1.5s, (b) $0.12 \mathrm{~s}$, (c) $1.62 \mathrm{~s}$, (d) $3.032 \mathrm{~s}$.

The transition of vapor bubble behaviors and the mean surface temperature of the micro-pin-finned chip (denoted as chip PF50-60) responding to the variation of gravity level for the heating dc current of $0.50 \mathrm{~A}$ (corresponding to a heat flux of $27.2 \mathrm{~W} / \mathrm{cm}^{2}$ ) are shown in Figs. 5 and 6 , respectively. The positions of Figs. $5(\mathrm{a})-5(\mathrm{~d})$ are marked on the curves of the mean temperature of Chip PF50-60 shown in Fig. 6. The liquid subcooling also keeps at about $41 \mathrm{~K}$. Just as the case of smooth chip, the bubbles generate and departure continuously from the heating surface caused by buoyancy forces before entering the microgravity condition (as shown in Fig. 5(a)). However, the bub- 
ble number is much larger than that for the smooth chip, indicating that the micro-pin-finned surface can provide a larger number of nucleation sites for enhancing boiling heat transfer performance. At about $0.12 \mathrm{~s}$ after entering the microgravity condition, the vapor bubbles begin to coalesce with each other to form several large bubbles attaching on the chip surface (as shown in Fig. 5(b)). Some small bubbles are in the departure state when entering the microgravity condition, so we can still see them departing from the heater surface at this time. With increasing time, the bubbles coalesce to form a large spherical bubble (as shown in Fig. 5(c)). However, the large bubble covering on the heater surface does not cause obvious increase of wall temperature, as shown in Fig. 6.

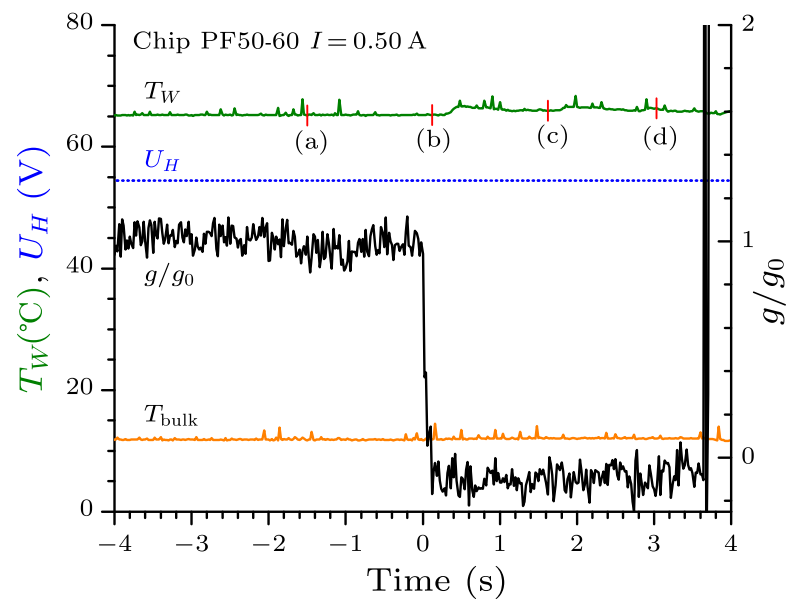

Fig. 6. Variations of surface temperature, heating voltage, and gravity for chip PF50-60.

The capillary force generated by the interface between the large bubble and the liquid of the microlayer beneath the bubble drives plenty of fresh liquid to contact with the superheated wall for vaporization through the regular interconnected structures formed by the micro-pin-fins, as well as improves the micro-convection heat transfer by the motion of liquid around the micro-pin-fins, as shown schematically in Fig. 7. Therefore, there is no deterioration of boiling heat transfer performance for the micro-pin-finned surface. The sufficient supply of bulk liquid to the heater surface guarantees the continuous growth of the large bubble. When the bubble size grows up to a certain value, the bubble departs away from the heater surface (as shown in Fig. 5(d)). Therefore, the heater surface temperature can keep almost constant under both gravity and microgravity conditions. The constant temperature makes the electric resistance of the micro-pin-finned chip constant, and thus the voltage across the chip does not change for the constant dc current input of $0.50 \mathrm{~A}$, as shown in Fig. 6. Although the micro-pin-finned chip has a slightly larger heat flux than the smooth chip, its temperature can still keep at a constant lower temperature of $63^{\circ} \mathrm{C}$ in micro- gravity. The boiling heat transfer coefficient reaches $38.8 \mathrm{~kW} / \mathrm{m}^{2} \cdot \mathrm{K}$. This differs greatly from that for the smooth chip. We can see from Fig. 4 that the wall temperature of Chip $\mathrm{S}$ increases continuously to a large value of $120^{\circ} \mathrm{C}$, resulting in a continuous increase of voltage across the chip for the constant dc current input of $0.40 \mathrm{~A}$. The boiling heat transfer coefficient at $120^{\circ} \mathrm{C}$ is only $3.7 \mathrm{~kW} / \mathrm{m}^{2} \cdot \mathrm{K}$, which is much lower than that of the micro-pin-finned chip. Therefore, the micro-pin-finned chip shows a much better boiling heat transfer performance than the smooth chip in microgravity.
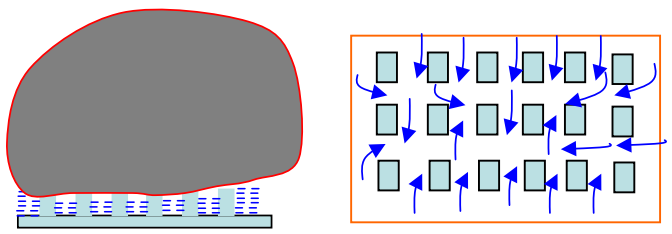

Fig. 7. Bulk liquid supply and micro-convection caused by capillary force.

In summary, the micro-pin-fined surface structure is supposed to provide large capillary force and small flow resistance, driving a plenty of bulk liquid to access the heater surface for evaporation in high heat flux region, which probably leads to a large bubble size for easy detachment and hence results in large boiling heat transfer enhancement. Since the capillary force is not related to the gravity level, the micro-pin-fined surface appears to be one promising enhanced surface for efficient electronic components cooling schemes not only in normal gravity but also under microgravity conditions, which is very helpful to reduce the cooling system weight in space and in planetary neighbors.

\section{References}

[1] Zhao J F, Li J, Yan N and Wang S F 2010 Chin. Phys. Lett. 27076401

[2] Oktay S 1982 Proceeding of 7th International Heat Transfer Conference (Munich 6-10 September 1982) p 113

[3] Hwang U P and Moran K F 1981 Heat Transfer Electron. Equip. ASME HTD 2053

[4] Kubo H, Takamatsu H and Honda H 1999 J. Enhanced Heat Transfer 6151

[5] O'Connor J P, You S M and Price D C 1995 IEEE Trans. Comp. Packageing Manufact. Tchnol. 18656

[6] Chang J Y and You S M 1996 ASME J. Heat Transfer 118 937

[7] Chang J Y and You S M 1997 Int. J. Heat Mass Transfer 404449

[8] Wei J J, Guo L J and Honda H 2005 Heat Mass Transfer 41744

[9] Wei J J and Honda H 2003 Int. J. Heat Mass Transfer 46 4059

[10] Ma A X, Wei J J, Yuan M Z and Fang J B 2009 Int. J. Heat Mass Transfer 522925

[11] Wei J J, Zhao J F, Yuan M Z and Xue Y F 2009 Microgravity Sci. Technol. 21 S159-S173

[12] Zhao J F, Li J and Yan N 2009 Microgravity Sci. Technol. $21 \mathrm{~S} 175$ 